\title{
Abnormal Activation of Glial Cells in the Brains of Prion Protein-deficient Mice Ectopically Expressing Prion Protein-like Protein, PrPLP/Dpl
}

\author{
Ryuichiro Atarashi, ${ }^{1}$ Suehiro Sakaguchi, ${ }^{1,3}$ Kazuto Shigematsu, ${ }^{2}$ Kazuhiko Arima, ${ }^{3}$ Nobuhiko \\ Okimura, ${ }^{3}$ Naohiro Yamaguchi, ${ }^{3}$ Aimin $\mathrm{Li}^{3}{ }^{3} \mathrm{Juraj}_{\text {Kopacek, }}{ }^{3,4}$ and Shigeru Katamine ${ }^{1,3}$ \\ ${ }^{1}$ Department of Bacteriology \\ ${ }^{2}$ Department of Pathology, Nagasaki University School of Medicine \\ ${ }^{3}$ Department of Molecular Microbiology and Immunology, Nagasaki University Graduate School of Medical \\ Sciences, Nagasaki, Japan \\ ${ }^{4}$ Department of Molecular Biology, Institute of Virology, Slovak Academy of Sciences, Brastislava, Slovakia \\ Contributed by C. Weissmann. Accepted October 25, 2001
}

\begin{abstract}
Background: Some lines of mice homozygous for a disrupted prion protein gene (Prnp), including Ngsk Prnp ${ }^{0 / 0}$ mice, exhibit Purkinje cell degeneration as a consequence of the ectopic overexpression of the downstream gene for prion protein-like protein (PrPLP/Dpl) in the brain, but others, such as Zrch I Prnp ${ }^{0 / 0}$ mice, show neither the neurodegeneration nor the expression of PrPLP/Dpl. In the present study, we found that Ngsk Prnp ${ }^{o / 0}$, but not Zrch I $P_{r n p}{ }^{0 / 0}$ mice, developed gliosis involving both astrocytes and microglia in the brain.

Materials and Methods: The brains from wild-type $\left(\right.$ Prn $\left.^{+/+}\right)$, Ngsk Prnp ${ }^{0 / 0}$, Zrch I Prnp $p^{0 / 0}$, and reconstituted Ngsk Prnp ${ }^{0 / 0}$ mice carrying a mouse PrP transgene, designated $\operatorname{Tg}(\mathrm{P})$ Ngsk Prnp $p^{0 / 0}$ mice, were subjected into Northern blotting and in situ hybridization using probes of glial fibrillary acidic protein (GFAP) and lysozyme M (LM) specific for astrocytes and microglia, respectively. Immunohis-
\end{abstract}

tochemistry was also performed on the brain sections using anti-GFAP and anti-F4/80 antibodies.

Results: Northern blotting demonstrated upregulated expression of the genes for GFAP and LM in the brains of Ngsk Prnp ${ }^{0 / 0}$, but not in Zrch I Prnp ${ }^{o / 0}$ mice. A transgene for normal mouse $\operatorname{PrP}^{\mathrm{C}}$ successfully rescued Ngsk Prnp $^{O / O}$ mice from the glial activation. In situ hybridization and immunohistochemistry revealed activated astrocytes and microglia mainly in the white matter of both the forebrains and cerebella. In contrast, there was no evidence of neuronal injury except for the Purkinje cell degeneration. Moreover, the glial cell activation was notable well before the onset of the Purkinje cell degeneration.

Conclusions: These findings strongly suggest that ectopic PrPLP/Dpl in the absence of $\operatorname{PrP}^{\mathrm{C}}$ is actively involved in the glial-cell activation in the brain.

\section{Introduction}

The cellular isoform of prion protein $\left(\mathrm{PrP}^{\mathrm{C}}\right)$, a membrane glycoprotein anchored by a glycosylphosphatidylinositol moiety, is highly expressed in the central nervous system (CNS), in particular on neurons. $\operatorname{PrP}^{\mathrm{C}}$ is known to play a crucial role in the pathogenesis of prion diseases $(1,2)$, but its physiological function remains to be clarified. We previously reported a line of $\operatorname{PrP}^{\mathrm{C}}$-deficient mice, designated Ngsk Prnp ${ }^{0 / 0}$ mice, that exhibited ataxia due to cerebellar Purkinje cell degeneration and demyelination in the spinal cord and peripheral nervous system at old age $(3,4)$. Subsequently, two other

Send correspondence and reprint requests to: Suehiro Sakaguchi, Department of Molecular Microbiology and Immunology, Nagasaki University Graduate School of Medical Sciences, Sakamoto 1-12-4, Nagasaki 852-8523, Japan. E-mail: suehirosngs@umin.ac.jp.

Aimin Li's current address: Department of Cell Biology and Physiology, Washington University School of Medicine, 660 South Elucid Avenue, St. Louis, MO 63110, USA. independent mouse lines, Rcm0 and Zrch II Prnp ${ }^{0 / 0}$ mice, were confirmed to develop similar neurodegeneration $(5,6)$. In contrast, another independent line, Zrch I Prnp ${ }^{0 / 0}$, revealed the demyelination and has never exhibited Purkinje cell degeneration (4). Behavioral and electrophysiological studies of the Zrch I Prnp ${ }^{0 / 0}$ mice demonstrated abnormal circadian rhythms (7) and impaired long-term potentiation in the hippocampus (8), respectively. In spite of the discrepancy in the ataxic phenotype, all of the neurological abnormalities, including the Purkinje cell degeneration in these $\operatorname{PrP}^{\mathrm{C}}$-deficient mice were subsequently rescued by the introduction of a transgene encoding wild-type $\operatorname{PrP}^{\mathrm{C}}(4,7,9)$, indicating the crucial role of $\operatorname{PrP}^{\mathrm{C}}$ in survival and various functions of neurons.

Others and we recently identified a novel gene, Prnd, that is localized $16 \mathrm{~kb}$ downstream of the murine PrP gene (Prnp) and encodes a PrP-like protein, PrPLP/Dpl $(5,10)$. This novel membrane glycoprotein is homologous to the C-terminal two-thirds of $\mathrm{PrP}$ 
with a $23 \%$ identity in the amino acid sequence. Interestingly, in the brains of Ngsk, Rcm0, and Zrch II $\mathrm{Prnp}^{0 / 0}$ mice, but not in those of Zrch I Prnp ${ }^{0 / 0}$ mice, unusual intergenic splicing between Prnp and Prnd occurred as a result of the deletion of a part of the Prnp intron 2 sequence, including its splicing acceptor $(5,10)$. As a consequence, the PrPLP/Dpl was ectopically expressed in neurons, under the control of the Prnp promoter (10). It is thus most likely that both the loss of $\operatorname{PrP}^{\mathrm{C}}$ and the ectopic expression of PrPLP/Dpl are necessary for the Purkinje cell degeneration in Ngsk Prnp ${ }^{o / O}$ mice. Rossi et al. recently confirmed the causal involvement of the ectopic PrPLP/Dpl in the Purkinje cell degeneration by demonstrating that the Zrch II Prnp ${ }^{0 / 0}$ mice transgenic for Prnd developed the Purkinje cell degeneration much earlier than Zrch II Prnp ${ }^{0 / 0}$ mice (6).

In the present study, we demonstrate glial-cell activation in the brains of Ngsk Prnp ${ }^{o / 0}$ mice, but not in those of Zrch I Prnp ${ }^{0 / 0}$ mice. The glial cell activation was not evident in the reconstituted Ngsk Prnp ${ }^{0 / 0}$ mice harboring a transgene encoding wild-type $\mathrm{PrP}^{\mathrm{C}}$. The results suggest an active role of the ectopic PrPLP/Dpl in the glial-cell activation in Ngsk Prnp ${ }^{0 / 0}$ mice.

\section{Materials and Methods}

\section{Mice}

Ngsk Prnp ${ }^{0 / 0}$ mice were generated as described previously (2). The reconstituted Ngsk Prnp ${ }^{0 / 0}$ mice, designated Tg(P) Ngsk Prnp ${ }^{0 / 0}$ mice, were generated by mating Ngsk Prnp ${ }^{0 / 0}$ mice with Tg(MoPrP-A)/FVB-B4053 mice $(4,11)$ carrying a mouse PrP-A transgene on the Zrch I Prnp ${ }^{o / 0}$ mouse background. Zrch I Prnp ${ }^{0 / 0}$ mice were obtained by mating $\mathrm{Tg}$ (MoPrP-A)/FVB-B4053 breeding pairs. Ngsk Prnp ${ }^{0 / 0}$ and Zrch I Prnp $p^{0 / 0}$ mice were intercrossed to obtain Ngsk/Zrch I Prnp ${ }^{0 / 0}$ mice.

\section{Northern Blot Analysis}

Total RNA was extracted using Trizol reagent (Gibco BRL Life Technologies, Inc., Grand Island, NY, USA), separated on a formaldehyde-denatured agarose gel, and blotted onto a Hybond $\mathrm{N}$ membrane (Amersham Pharmacia Biotech, Buckinghamshire, UK) with $10 \times$ SSC. The RNA was fixed onto the membrane by ultraviolet light at 70,000 microjoules per $\mathrm{cm}^{2}$ for 2 min (UVP, Ltd., Upland, USA). Next, the membrane was subjected to a prehybridization procedure for $4 \mathrm{hr}$ at $45^{\circ} \mathrm{C}$ in the buffer $(5 \times$ SSPE $/ 0.5 \%$ SDS $/ 50 \%$ formamide $/ 5 \times$ Denhardt's solution $/ 10 \%$ dextran sulphate $/ 100 \mu \mathrm{g} / \mathrm{ml}$ salmon sperm DNA), and then hybridized using an appropriate ${ }^{32} \mathrm{P}$-labelled DNA probe (BcaBEST Labelling Kit, TaKaRa, Tokyo, Japan) overnight at $45^{\circ} \mathrm{C}$ in the same buffer. The membrane was washed twice in $2 \times \mathrm{SSC} / 0.1 \%$ SDS at room temperature for $10 \mathrm{~min}$, once in $1 \times$ SSC $/ 0.1 \%$ SDS, and twice in $0.1 \times$ SSC $/ 0.1 \%$ SDS at $65^{\circ} \mathrm{C}$ for 15 min. Signals were detected by BAS 5000 (Fuji, Tokyo, Japan) or autoradiography on Konica $\mathrm{X}$-ray film.

\section{In Situ Hybridization}

Brains were fixed for $16 \mathrm{hr}$ in $4 \%$ buffered-paraformaldehyde ( $\mathrm{pH} 7.4)$ at $4^{\circ} \mathrm{C}$, embedded in paraffin and sliced to $5-\mu \mathrm{m}$ thickness. The sections were deparaffinized, digested with $8 \mathrm{mg} / \mathrm{ml}$ pepsin and $10 \mathrm{mg} / \mathrm{ml}$ proteinase $\mathrm{K}$ for $10 \mathrm{~min}$ at $37^{\circ} \mathrm{C}$, and soaked for $10 \mathrm{~min}$ in $0.25 \%$ acetic anhydride/ $0.1 \mathrm{mM}$ triethanolamine hydrochloride ( $\mathrm{pH} 8.0) / 0.9 \% \mathrm{NaCl}$. The cRNA probes were labelled with digoxigenin (DIG)UTP (Roche Diagnostics, Mannheim, Germany) using T7 or T3 polymerase (Gibco BRL Life Technologies, Inc.). The tissue sections were subjected to hybridization with the labelled cRNA probes in buffer $(50 \%$ formamide/10 $\mathrm{mM}$ Tris- $\mathrm{HCl} \quad[\mathrm{pH} \quad 7.5] / 1 \quad \mathrm{mM}$ EDTA/0.6M NaCl $/ 0.5 \mathrm{mg} / \mathrm{ml}$ yeast tRNA $/ 0.25 \mathrm{mg} / \mathrm{ml}$ salmon sperm DNA/1\% skim milk/0.25\% SDS/5 $\times$ Denhart's solution) at $50^{\circ} \mathrm{C}$ for $16 \mathrm{hr}$. The sections were washed several times in $4 \times$ SSC, and immersed in $50 \%$ formamide $/ 2 \times \mathrm{SSC}$ at $50^{\circ} \mathrm{C}$ for $30 \mathrm{~min}$. They were digested by $20 \mu \mathrm{g} / \mathrm{ml}$ RNase $\mathrm{A}$ at $37^{\circ} \mathrm{C}$ for 30 min and washed in $0.2 \times \mathrm{SSC}$ at $60^{\circ} \mathrm{C}$ for $20 \mathrm{~min}$. Signals were detected by an enzyme-linked immunosorbent assay using alkaline phosphatase conjugated anti-DIG Fab fragments (1:500, Roche Diagnostics) and nitro blue tetrazolium/5-bromo-4-chloro-3-indolyl phosphate (NBT/BCIP).

\section{Probes}

The LM probe used has been described previously (12). The GFAP probe was a 791-bp DNA fragment spanning nucleotide 466 to 1256 of the cDNA (Accession No. K01347), the $\mathrm{IP}_{3} \mathrm{R} 1$ probe a 502-bp fragment from nucleotide 2854 to 3355 of the cDNA (Accession No. X15373), the synaptophysin probe a 677-bp fragment from nucleotide 1413 to 2088 of the cDNA (Accession No. X95818), the MBP probe a 590-bp fragment from nucleotide 340 to 930 of the cDNA (Accession No. M15060), the PLP probe a 309-bp fragment from nucleotide 834 to 1142 of the cDNA (Accession No. M37335), and the GAPDH probe a 677-bp fragment from nucleotide 1413 to 2088 of the cDNA (Accession No. M32599).

\section{Immunohistochemistry}

Deparaffinized sections were digested with $1 \mathrm{mg} / \mathrm{ml}$ trypsin for $15 \mathrm{~min}$ at $37^{\circ} \mathrm{C}$, and then placed in $3 \%$ $\mathrm{H}_{2} \mathrm{O}_{2}$ in methanol for $30 \mathrm{~min}$ at room temperature to abolish endogenous peroxidase activity. After treatment with normal rabbit serum for $30 \mathrm{~min}$, the tissue sections were incubated overnight at $4^{\circ} \mathrm{C}$ with antiGFAP (1:50 [Dako, Kyoto, Japan]) and anti-F4/80 antigen (1:20 [Serotec, Ltd., Oxford, United Kingdom]). To detect GFAP immunoreactivity we used the Polymer-Immuno Complex method, in accordance with the manufacturer's recommendations (Dako). For F4/80, the tissue sections were subsequently incubated with biotinylated rabbit antirat immunoglobulin (mouse adsorbed, [Dako]) at room temperature for $30 \mathrm{~min}$. The antibody-bound 
peroxidase was revealed with $0.04 \%$ diaminobenzidine (Sigma Chemical Co., St. Louis, MO).

\section{Results}

Upregulation of Glial Cell-specific Gene Expression in the Brains of Aged Ngsk Prnp ${ }^{0 / 0}$ Mice

We first examined expression levels of the glial fibrillary acidic protein (GFAP) and lysozyme $M$ (LM) mRNAs specific to astrocytes and microglia, respectively, in the forebrains and cerebella of 102-week-old Ngsk $P_{r n p}{ }^{0 / 0}$ mice. Total RNA isolated from the pooled forebrains and cerebella of Ngsk Prnp ${ }^{0 / 0}$ and age-matched wild-type $\left(\mathrm{Prnp}^{+/+}\right)$mice was subjected to Northern blotting. As shown in Fig. la, the GFAP and LM mRNA levels were elevated in both tissue types in the Ngsk Prnp ${ }^{0 / 0}$ mice. Densitometric analysis estimated that, compared with those of the Prnp ${ }^{+++}$mice, GFAP mRNA was increased 2.5- and 2.7-times, and LM mRNA 2.7- and 3.0-times, in the forebrains and cerebella, respectively. In contrast, the expression of inositol 1,4,5-trisphosphate receptor type $1 \quad\left(\mathrm{IP}_{3} \mathrm{R} 1\right)$ mRNA, a specific marker for Purkinje cells, was decreased in the cerebella of Ngsk Prnp ${ }^{0 / 0}$ mice (Fig. la).

In situ hybridization and immunohistochemistry on the brain sections of Ngsk Prnp ${ }^{0 / 0}$ mice at 92 weeks of age revealed numerous astrocytes expressing GFAP mRNA and its product mainly in the major white matter areas including the corpus callosum, fimbria hippocampus, and internal and external capsula, and the cerebellum (Fig. 2). While a number of astrocytes was also seen in the brain tissues of the age-matched

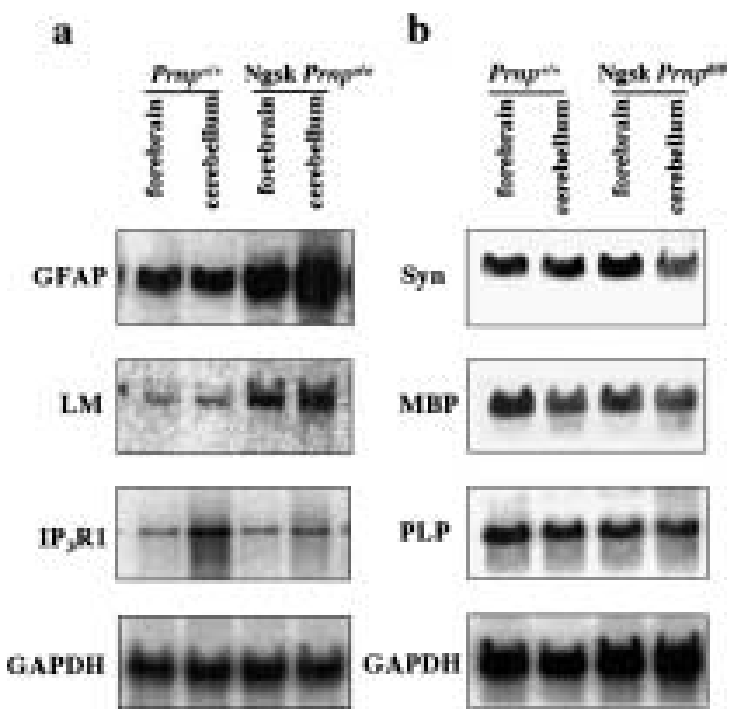

Fig. 1. Glia-specific genes in the forebrain and cerebellum are upregulated in aged Ngsk Prnp ${ }^{O / O}$ mice. $10 \mu \mathrm{g}$ of total RNA extracted from the pooled brain tissues of 102-week-old Ngsk Prnp ${ }^{0 / 0}$ and Prnp ${ }^{+/+}$mice were subjected to Northern blotting using appropriate probes. The GFAP, LM, and $\mathrm{IP}_{3} \mathrm{R} I$ probes were used in (a) and synaptophysin (Syn), MBP, and PLP probes in (b). The integrity and quantity of RNA were verified with a glyceraldehydes-3-phosphate dehydrogenase (GAPDH) probe on the same membrane.
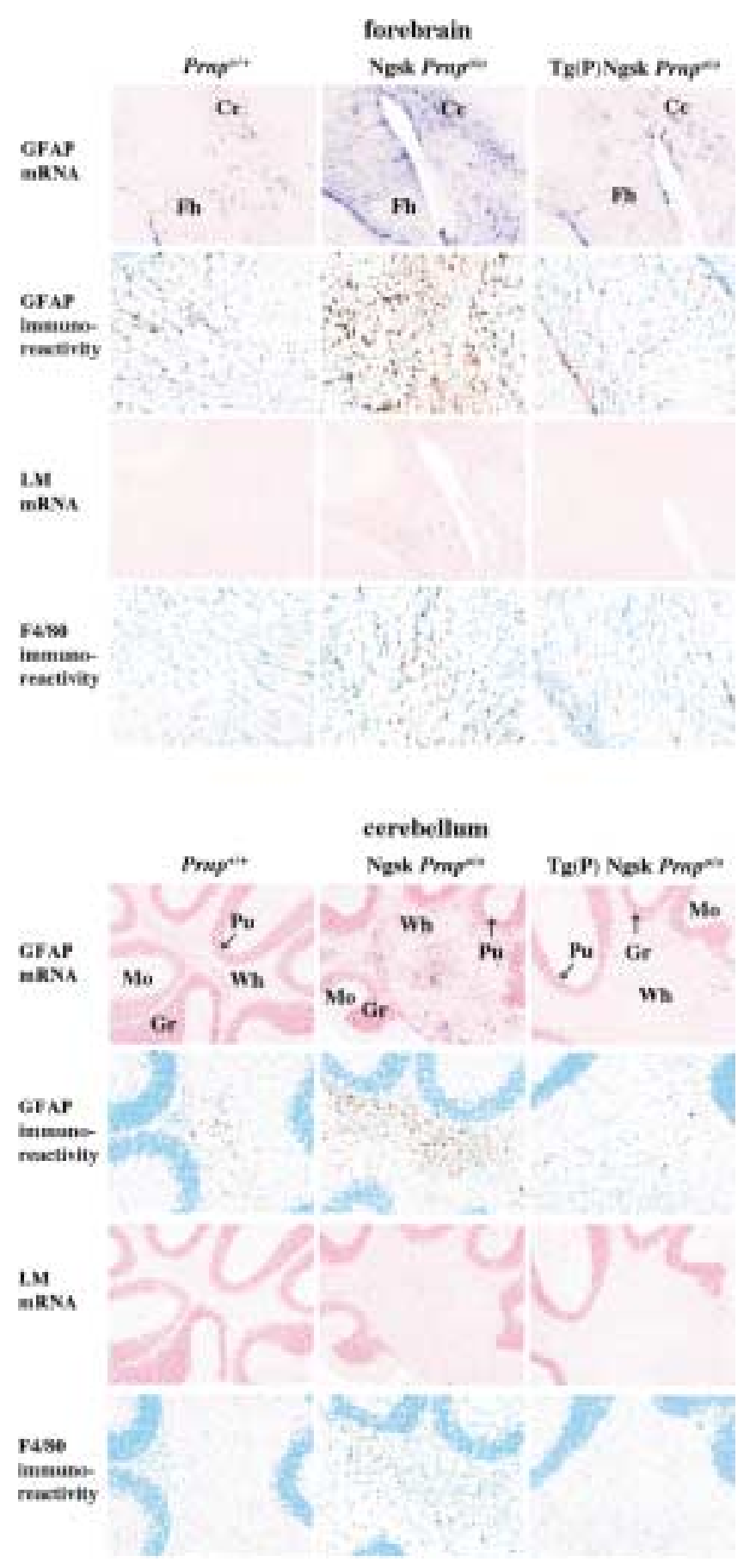

Fig. 2. Gliosis of astrocytes and microglia in the brains of aged Ngsk Prnp ${ }^{o / 0}$ mice. Localizations of mRNAs for GFAP and LM, and immunoreactivities to GFAP and F4/80 in the forebrains and cerebella of 92-week-old Prnp ${ }^{+/+}$, Ngsk Prnp $^{0 / 0}$ and Tg(P) Ngsk Prnp ${ }^{0 / 0}$ mice are shown. Both hybridized and immunoreactive signals were localized mainly in the cerebral and cerebellar white matter. The number of positive cells and the intensity of their signals were markedly increased in the Ngsk Prnp ${ }^{0 / 0}$ mice compared with Prnp ${ }^{+/+}$ and Tg(P) Ngsk Prnp ${ }^{0 / 0}$ mice. Cc; corpus callosum, Fh; fimbria hippocampus, Gr; granular layer, Mo; molecular layer, $\mathrm{Pu}$; Purkinje cell layer, Wh; cerebellar white matter. Original magnification: $\times 13.2$ for in situ hybridization and $\times 25$ for immunohistochemistry. 
$\mathrm{Prnp}^{+/+}$mice, Ngsk Prnp ${ }^{0 / 0}$ mice revealed much larger numbers of hypertrophic astrocytes stainable for GFAP. LM mRNA and F4/80 protein expressed by microglia were also concentrated in the white matter, and the number of positive cells was markedly increased in the Ngsk Prnp ${ }^{0 / 0}$ mice.

No Evidence for Neuronal Injury Other Than Purkinje Cell Degeneration in the Brains of Aged Ngsk Prnp ${ }^{0 / 0}$ Mice

Glial cell activation usually occurs as a reaction to neuronal injury. However, extensive histological studies have failed to identify any neuronal damage other than Purkinje cell degeneration in the brains of Ngsk $P_{r n p^{0 / 0}}$ mice. Luxol fast blue staining of myelin sheaths in the forebrains of mice aged 92 weeks was normal (data not shown). To further examine whether there is any submicroscopic injury to the neuronal architecture in the brains of Ngsk Prnp ${ }^{0 / 0}$ mice, we evaluated the levels of mRNA for a neuronal protein, synaptophysin, and two major components of myelin, myelin basic protein (MBP) and proteolipid protein (PLP) by Northern blotting using total RNA extracted from the pooled forebrains and cerebella of 102-week-old Ngsk Prnp ${ }^{0 / 0}$ mice. Similarly to the $\mathrm{IP}_{3} \mathrm{Rl}$ mRNA, the expression of synaptophysin was normal in the forebrains but reduced in the cerebella of 102-week-old Ngsk Prnp ${ }^{0 / 0}$ mice (Fig. 1b). On the other hand, there was no difference in the levels of MBP and PLP mRNAs between Ngsk Prnp ${ }^{o / 0}$ and agematched Prnp ${ }^{+/+}$mice. These observations were also confirmed by in situ hybridization (data not shown).

Glial-cell Activation Occurs Well Before the Onset of Purkinje Cell Degeneration in the Brains of Ngsk Prnp $^{0 / 0}$ Mice

We monitored kinetics of the GFAP and LM mRNA levels in the pooled forebrains and cerebella of Ngsk $\mathrm{Prnp}^{\circ / 0}$ and wild-type mice at various ages between 3 and 102 weeks. In the Ngsk Prnp ${ }^{o / 0}$ mice, however, increased levels of GFAP mRNA appeared as early as 8 and 3 weeks in the forebrains and cerebella, respectively, and the transcript accumulated more rapidly in the tissues (Fig. 3a, b). Increased levels of LM mRNA were also seen from 22 and 8 weeks in a

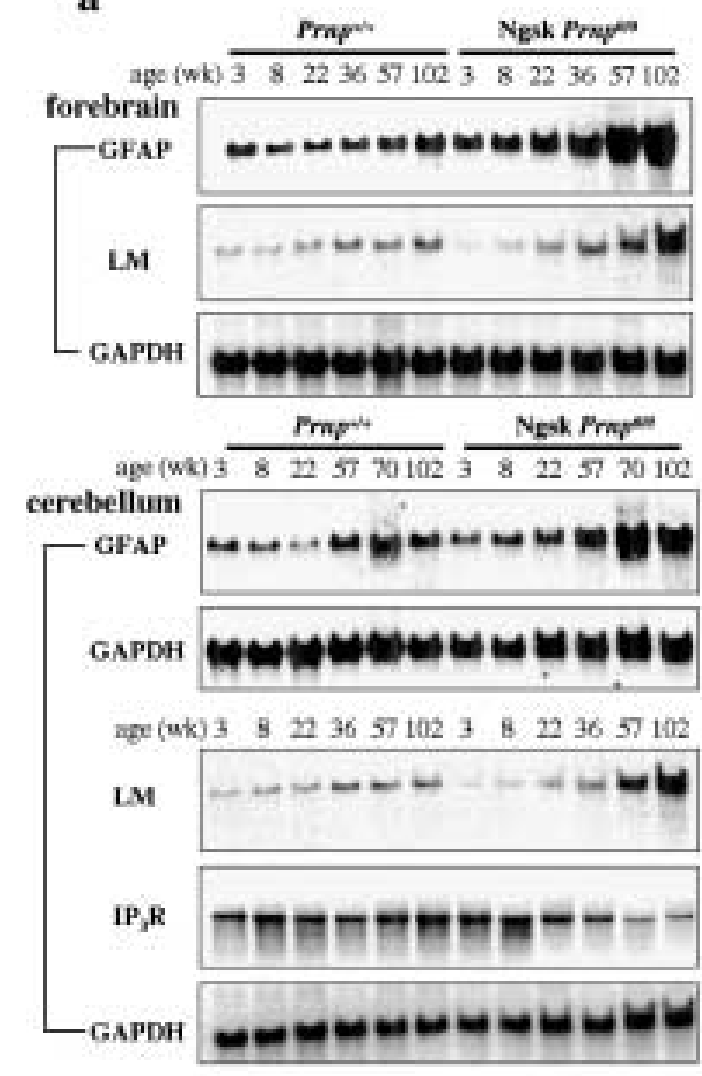

b
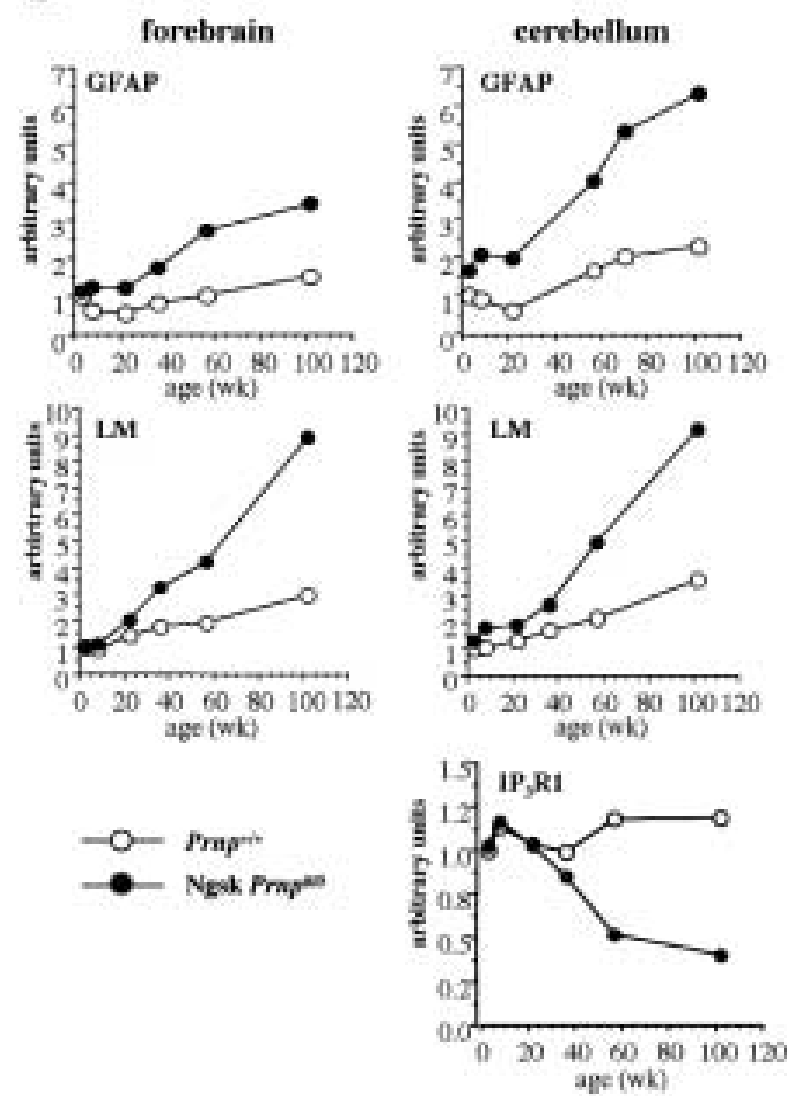

Fig. 3. Kinetic analysis of the glial cell-specific gene expression in the forebrains and cerebella of Ngsk Prnp ${ }^{0 / 0}$ mice. (a) The levels of transcripts for GFAP, LM, and $\mathrm{IP}_{3} \mathrm{R} 1$ were compared between Ngsk Prnp ${ }^{0 / 0}$ and Prnp ${ }^{+/+}$brain tissues at different ages (wk). $10 \mu \mathrm{g}$ of total RNA extracted from the pooled tissues were subjected to Northern blotting. The integrity and quantity of the RNA were verified with GAPDH probe on the same membrane. (b) Kinetics of the mRNAs for GFAP, LM, and IP ${ }_{3} \mathrm{R} I$ were compared between Ngsk Prnp ${ }^{0 / 0}$ (closed circles) and Prnp ${ }^{+/+}$(open circles) mice. The intensities of Northern blot signals shown in (a) were quantified using BAS 5000, standardized with GAPDH mRNA level, and expressed as arbitrary units in comparison with the value of Prnp ${ }^{+/+}$mice at 3 weeks of age. 
the forebrains and cerebella, respectively, and levels continued to rise until 102 weeks. In contrast, the decline of $\mathrm{IP}_{3} \mathrm{R} 1$ mRNA in the cerebella of Ngsk $\mathrm{Prnp}^{0 / 0}$ mice became evident at 36 weeks, suggesting that glial-cell activation occurs before the onset of the Purkinje cell degeneration.

\section{A Transgene Encoding Wild-type PrP $P^{C}$ Normalizes GFAP and LM mRNA Levels in the Brains of Ngsk Prnp $^{0 / 0}$ Mice}

In order to elucidate whether the activation of GFAP and LM genes is associated with the loss of $\operatorname{PrP}^{\mathrm{C}}$, we examined the reconstituted mice, $\operatorname{Tg}(\mathrm{P})$ Ngsk Prnp $^{0 / 0}$, which carried several copies of a transgene encoding wild-type mouse $\operatorname{PrP}^{\mathrm{C}}$ on the genetic background of Ngsk Prnp ${ }^{0 / 0}$. In situ hybridization exhibited a high level of PrP mRNA widely distributed in the neurons and glial cells thoughout the CNS of $\mathrm{Tg}(\mathrm{P})$ Ngsk Prnp ${ }^{0 / 0}$ mice (data not shown). Neurons, especially in the hippocampus and cerebellar Purkinje cell layer, were heavily hybridized. Histologic examination confirmed that Purkinje cells were preserved in all areas of the cerebellum of the $\mathrm{Tg}(\mathrm{P})$ Ngsk Prnp ${ }^{0 / 0}$ mice (data not shown). Total RNAs from the brains of three each of 80 -week-old Prnp $^{+/+}$, Ngsk Prnp ${ }^{0 / 0}$, and Tg(P) Ngsk Prnp ${ }^{0 / 0}$ mice were subjected to Northern blotting with the GFAP and LM probes. The elevated expression of GFAP and LM mRNAs found in the Ngsk Prnp ${ }^{0 / 0}$ mice declined in the $\operatorname{Tg}(\mathrm{P})$ Ngsk Prnp ${ }^{0 / 0}$ mice to a level similar to that of the Prnp ${ }^{+/+}$mice (Fig. 4a, b). Additionally, the number of astrocytes and microglia in the $\mathrm{Tg}(\mathrm{P})$ Ngsk Prnp ${ }^{0 / 0}$ mice was decreased to the level seen in the $\mathrm{Prnp}^{+/+}$mice, as shown by in situ hybridization and immunohistochemistry (Fig. 2).

The Level of Glial-cell Activation Correlates with that of Ectopic Expression of PrPLP/Dpl

To further elucidate the mechanisms for the glial-cell activation, we examined the expression levels of GFAP and LM mRNAs in the brains of another independent mouse line, Zrch I Prnp ${ }^{o / 0}$, which has neither exhibited ataxia nor Purkinje cell degeneration, and heterozygous Ngsk/Zrch I Prnp ${ }^{0 / 0}$ mice. The heterozygous mice developed the Purkinje cell degeneration much later than the Ngsk Prnp ${ }^{0 / 0}$ mice (data not shown). Although the Ngsk Prnp ${ }^{0 / 0}$ mice expressed abundant PrPLP/Dpl mRNA in the brains, the Zrch I $\operatorname{Prnp}^{0 / 0}$ mice expressed no detectable PrPLP/Dpl mRNA and the Ngsk/Zrch I Prnp ${ }^{0 / 0}$ mice revealed half the level of PrPLP/Dpl mRNA compared with the Ngsk Prnp ${ }^{0 / 0}$ mice (Fig. 5a). The expression levels of GFAP and LM mRNAs correlated well with that of PrPLP/DpL mRNA. The Zrch I Prnp ${ }^{0 / 0}$ mice aged 70 weeks showed no upregulation of the GFAP and LM mRNAs, exhibiting levels similar to those of agematched Prnp ${ }^{+/+}$mice (Fig. 5a, b). The Ngsk/Zrch I $\mathrm{Prnp}^{0 / 0}$ mice exhibited levels of GFAP and LM mRNAs between those of the Ngsk Prnp ${ }^{0 / 0}$ and Prnp $^{+/+}$mice (Fig. 5a, b).

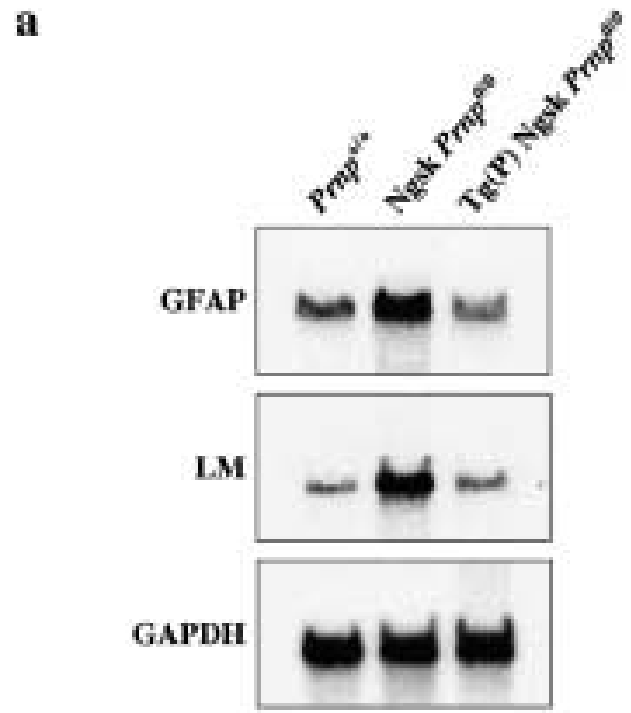

b

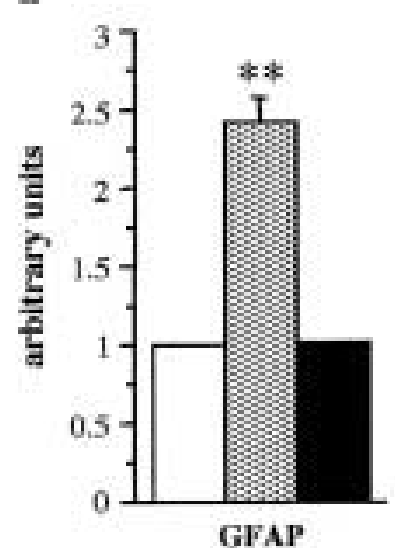

GFAP

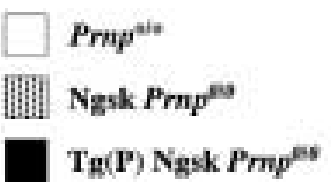

Fig. 4. A wild-type mouse PrP transgene normalizes the level of glial cell-specific gene expression in the brains of Ngsk Prnp ${ }^{o / o}$ mice. (a) $10 \mu \mathrm{g}$ of total RNA extracted from the total brain tissues of 80-week-old Prnp ${ }^{+/+}$, Ngsk Prnp ${ }^{0 / 0}$, and $\mathrm{Tg}(\mathrm{P})$ Ngsk Prnp ${ }^{0 / 0}$ mice were subjected to Northern blotting using the GFAP and LM probes. The integrity and quantity of RNA were verified with GAPDH probe on the same membrane. (b) The intensities of Northern blot signals shown in (a) were quantified using BAS 5000, the mRNA levels standardized with GAPDH mRNA, and expressed as arbitrary units in comparison with the values of Prnp ${ }^{+/+}$mice. Three brains from each line were analyzed by ANOVA. ${ }^{* *}$ represents $\mathrm{p}<0.01$.

\section{Discussion}

In the present study, we demonstrated glial-cell activation, or gliosis, with the upregulated expression of both astrocyte- and microglia-specific genes encoding GFAP and LM, respectively, in the brains of Ngsk Prnp $^{o / 0}$ mice. A transgene for wild-type $\operatorname{PrP}^{\mathrm{C}}$ rescued 

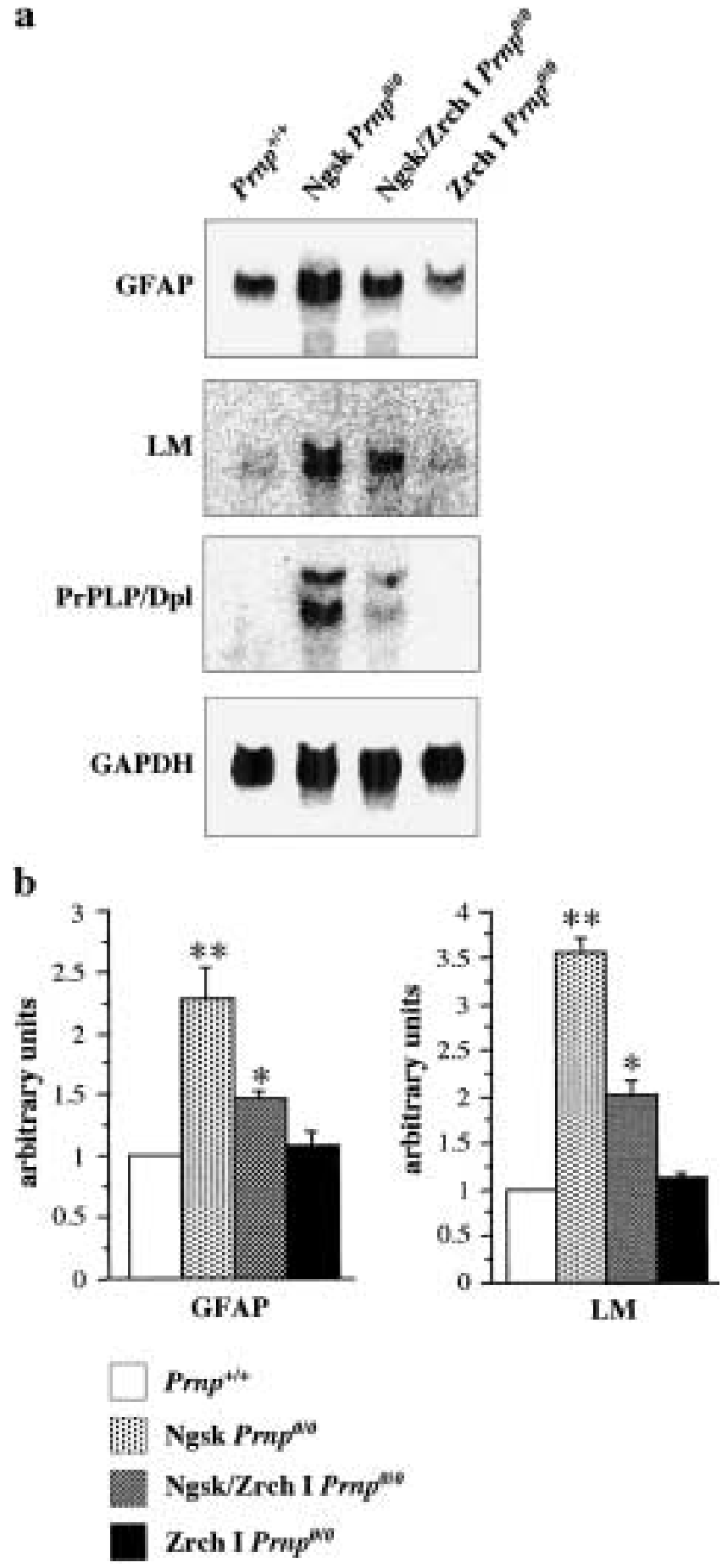

Fig. 5. Glial cell-specific genes are not upregulated in the brains of Zrch I Prnp ${ }^{o / o}$ mice lacking Purkinje cell degeneration. (a) The levels of transcripts for GFAP and LM were compared by Northern blotting among total brain tissues from Prnp ${ }^{+/+}$ (lane 1), Ngsk Prnp ${ }^{o / 0}$ (lane 2), Ngsk/Zrch I Prnp ${ }^{o / 0}$ (lane 3), and Zrch I Prnp ${ }^{\circ / 0}$ (lane 4) at 70 weeks of age. $10 \mu \mathrm{g}$ of total RNA were blotted on each lane, and the integrity and quantity were verified with GAPDH probe on the same membrane. (b) The intensities of Northern blot signals were quantified and plotted as described. The levels of transcripts for GFAP and LM were compared among Prnp $^{+/+}$, Ngsk Prnp ${ }^{0 / 0}$, Ngsk/Zrch I Prnp ${ }^{0 / 0}$, and Zrch Prnp ${ }^{0 / 0}$ mice at 70 weeks of age by using arbitrary units and analyzed by ANOVA $(\mathrm{n}=3)$. **represents $\mathrm{p}<0.01 ;{ }^{*}$ represents $\mathrm{p}<0.05$. the mice from the abnormal glial-cell activation. The finding that Zrch I Prnp ${ }^{0 / 0}$ mice did not reveal such a phenotype, however, indicates that the loss of $\operatorname{PrP}^{\mathrm{C}}$ is indispensable, but not the only factor involved, in the glial cell activation. The heterozygous Ngsk/Zrch I Prnp ${ }^{o / 0}$ mice exhibited levels of GFAP and LM expression in the brains between those of Ngsk Prnp ${ }^{0 / 0}$ and Zrch I Prnp ${ }^{0 / 0}$ mice, strongly suggesting the involvement of an additional factor(s) in the Ngsk $P_{r n p}{ }^{0 / 0}$ mice. We previously demonstrated that the disrupted Ngsk Prnp allele but not Zrch I Prnp ${ }^{0 / 0}$ allele expressed PrPLP/Dpl ectopically in brains, through intergenic mRNA splicing between Prnp and Prnd (10). The ectopically expressed PrPLP/Dpl is likely to play an active role in the glial-cell activation in Ngsk Prnp ${ }^{0 / 0}$ mice.

Ectopic expression of PrPLP/Dpl is known to be closely associated with the Purkinje cell degeneration in the ataxic lines of Prnp $p^{0 / 0}$ mice $(5,6,10)$. It is conceivable that the gliosis in the brains of Ngsk Prnp $^{o / 0}$ mice occurs as a consequence of neuronal damage. Accumulating evidence has suggested that $\operatorname{PrP}^{\mathrm{C}}$ binds copper through its histidine-rich octapeptide repeat region (13-15). Herms et al. hypothesized that $\operatorname{PrP}^{\mathrm{C}}$ may recapture copper released into the synaptic cleft and take it up into the presynaptic cytosol (16). The reduced activity of cytosolic copper-dependent superoxide dismutase in the brains of Prnp ${ }^{0 / 0}$ mice (17) is consistent with a functional link between copper metabolism and $\operatorname{PrP}^{\mathrm{C}}$ in neuronal cells, and is likely to be involved in the increased susceptibility of cultured Prnp ${ }^{0 / 0}$ neurons to oxidative stress. Moreover, Wong et al. recently reported that the brains of Prnp ${ }^{0 / 0}$ mice ectopically expressing PrPLP/Dpl revealed much higher levels of protein oxidation and lipid peroxidation than those of Prnp ${ }^{0 / 0}$ mice lacking PrPLP/Dpl (18). Weissmann and colleagues have proposed an active role of PrPLP/Dpl in the neurodegeneration in the Prnp $^{0 / 0}$ mice (19). They hypothesize the existence of a ligand which interacts with $\operatorname{PrP}^{\mathrm{C}}$ to elicit a signal essential for the survival of neurons, and another PrP-like molecule capable of binding to the putative ligand but with lower affinity. In Zrch I Prnp ${ }^{o / 0}$ mice, the association between the PrP-like molecule and the ligand would elicit the survival signal, but in Ngsk Prnp ${ }^{0 / 0}$ mice, the overexpression of PrPLP/Dpl would prevent the interaction, resulting in the Purkinje cell degeneration. It is possible that not only Purkinje cells but also other neurons in Ngsk Prnp ${ }^{0 / 0}$ mice may be affected by the ectopic PrPLP/Dpl to various degrees, leading to the marked gliosis in the brains.

Another intriguing possibility is a direct effect of the ectopic PrPLP/Dpl on the glial cells in the absence of $\mathrm{PrP}^{\mathrm{C}}$. Activated astrocytes and microglia were distributed throughout the forebrains and cerebella of aged Ngsk Prnp ${ }^{0 / 0}$ mice, mainly in the white matter. However, there was no histological evidence for neurodegeneration or demyelination other than 
the Purkinje cell degeneration. In contrast to the reduced levels of $\mathrm{IP}_{3} \mathrm{R} I$ and synaptophysin mRNAs in the cerebellum, representing the Purkinje cell degeneration, the synaptophysin mRNA level in the forebrain appeared to be normal. Transcripts for two major myelin components, MBP and PLP, were expressed at normal levels in both the forebrain and cerebellum. The expression profiles of these genes argues against the presence of submicroscopic neuronal injury other than the Purkinje cell degeneration. Moreover, a kinetic analysis demonstrated glialcell activation well before the onset of Purkinje cell degeneration in the Ngsk Prnp ${ }^{0 / 0}$ mice. It is thus conceivable that the glial-cell activation is primarily induced by the ectopic PrPLP/Dpl in the absence of $\operatorname{PrP}^{\mathrm{C}}$ rather than as a consequence of neuronal injury.

Astrocytes were reported to physiologically express PrP mRNA in vivo (20). We detected abundant PrPLP/Dpl mRNA in the primary culture of astrocytes derived from the Ngsk Prnp ${ }^{0 / 0}$ mice (data not shown). The ectopic PrPLP/Dpl on the surface of glial cells in the absence of $\operatorname{PrP}^{\mathrm{C}}$ may be the cause of the abnormal cell activation. An alternative possibility is that $\operatorname{PrP}^{\mathrm{C}}$ on the surface of neurons may be involved in the communication with glial cells, and the loss of $\mathrm{PrP}^{\mathrm{C}}$ together with ectopic PrPLP/Dpl on the neuronal surface may result in the glial-cell activation. Targeted expression of $\mathrm{PrP}^{\mathrm{C}}$ in either glial cells or neurons of Ngsk Prnp ${ }^{o / o}$ mice would be useful to elucidate mechanisms of the glial-cell activation.

It is noteworthy that not only astrocytes but also microglia were activated in the brains of Ngsk Prnp ${ }^{0 / 0}$ mice. Activated microglia are thought to be involved in the etiology of various neurodegenerative conditions by their production of neurotoxic substances (21-23). For instance, we recently demonstrated that microglial production of lysosomal hydrolases, a perforin-like protein, and reactive oxygen species was closely correlated with the onset and progression of pathological changes in an experimental prion disease (12). The decreased expression of $I_{3} R 1$ mRNA was evident well after the activation of LM gene, suggesting that the activated microglia might play a role in the Purkinje cell degeneration in Ngsk Prnp ${ }^{o / 0}$ mice. The elucidation of the mechanisms of the glialcell activation in Ngsk $\operatorname{Prnp}^{0 / 0}$ mice might provide insights into the understanding of not only the physiological functions of $\mathrm{PrP}^{\mathrm{C}}$ and PrPLP/Dpl but also the pathogenesis of neurodegenerative disorders, including prion diseases.

\section{Acknowledgments}

We are grateful to Prof. Charles Weissmann for his review of this manuscript and Amanda Nishida for help in preparation of the manuscript. This work was supported in part by grants from the Ministry of Education, Culture, Sports, Science and Technology, the Ministry of Health, Labour and Welfare, and the Ministry of Agriculture, Forestry and Fisheries of Japan.

\section{References}

1. Büeler H, Aguzzi A, Sailer A, et al. (1993) Mice devoid of PrP are resistant to scrapie. Cell 73: 1339-1347.

2. Sakaguchi S, Katamine S, Shigematsu K, et al. (1995) Accumulation of proteinase K-resistant prion protein (PrP) is restricted by the expression level of normal PrP in mice inoculated with a mouse-adapted strain of the Creutzfeldt-Jakob disease agent. J. Virol. 69: 7586-7592.

3. Sakaguchi S, Katamine S, Nishida N, et al. (1996) Loss of cerebellar Purkinje cells in aged mice homozygous for a disrupted PrP gene. Nature 380: 528-531.

4. Nishida N, Tremblay P, Sugimoto T, et al. (1999) A mouse prion protein transgene rescues mice deficient for the prion protein gene from purkinje cell degeneration and demyelination. Lab. Invest. 79: 689-697.

5. Moore RC, Lee IY, Silverman GL, et al. (1999) Ataxia in prion protein (PrP)-deficient mice is associated with upregulation of the novel PrP-like protein doppel. J. Mol. Biol. 292: 797-817.

6. Rossi D, Cozzio A, Flechsig E, et al. (2001) Onset of ataxia and Purkinje cell loss in PrP null mice inversely correlated with Dpl level in brain. Embo. J. 20: 694-702.

7. Tobler I, Gaus SE, Deboer T, et al. (1996) Altered circadian activity rhythms and sleep in mice devoid of prion protein. $\mathrm{Na}$ ture 380: 639-642.

8. Collinge J, Whittington MA, Sidle KC, et al. (1994) Prion protein is necessary for normal synaptic function. Nature 370: 295-297.

9. Whittington MA, Sidle KC, Gowland I, et al. (1995) Rescue of neurophysiological phenotype seen in PrP null mice by transgene encoding human prion protein. Nat. Genet. 9: 197-201.

10. Li A, Sakaguchi S, Atarashi R, et al. (2000) Identification of a novel gene encoding a PrP-like protein expressed as chimeric transcripts fused to PrP exon $1 / 2$ in ataxic mouse line with a disrupted PrP gene. Cell. Mol. Neurobiol. 20: 553- 567.

11. Telling GC, Haga T, Torchia M, et al. (1996) Interactions between wild-type and mutant prion proteins modulate neurodegeneration in transgenic mice. Genes Dev. 10: 1736-1750.

12. Kopacek J, Sakaguchi S, Shigematsu K, et al. (2000) Upregulation of the genes encoding lysosomal hydrolases, a perforin- like protein, and peroxidases in the brains of mice affected with an experimental prion disease. J. Virol. 74: 411-417.

13. Brown DR, Qin K, Herms JW, et al. (1997) The cellular prion protein binds copper in vivo. Nature 390: 684-687.

14. Hornshaw MP, McDermott JR, Candy JM. (1995) Copper binding to the $\mathrm{N}$-terminal tandem repeat regions of mammalian and avian prion protein. Biochem. Biophys. Res. Commun. 207: 621-629.

15. Stöckel J, Safar J, Wallace AC, et al. (1998) Prion protein selectively binds copper(II) ions. Biochemistry 37: 7185-7193.

16. Herms J, Tings T, Gall S, et al. (1999) Evidence of presynaptic location and function of the prion protein. J. Neurosci. 19: 8866-8875.

17. Brown DR, Schulz-Schaeffer WJ, Schmidt B, Kretzschmar HA. (1997) Prion protein-deficient cells show altered response to oxidative stress due to decreased SOD-1 activity. Exp. Neurol. 146: 104-112.

18. Wong BS, Liu T, Paisley D, et al. (2001) Induction of HO-1 and NOS in doppel-expressing mice devoid of PrP: implications for doppel function. Mol. Cell. Neurosci. 17: 768- 775.

19. Weissmann C, Aguzzi A. (1999) Perspectives: neurobiology. PrP's double causes trouble. Science 286: 914-915.

20. Moser M, Colello RJ, Pott U, Oesch B. (1995) Developmental expression of the prion protein gene in glial cells. Neuron 14: 509-517.

21. Dickson DW, Lee SC, Mattiace LA, et al. (1993) Microglia and cytokines in neurological disease, with special reference to AIDS and Alzheimer's disease. Glia 7: 75-83.

22. Kreutzberg GW. (1996) Microglia: a sensor for pathological events in the CNS. Trends Neurosci. 19: 312-318.

23. Brown DR, Kretzschmar HA. (1997) Microglia and prion disease: a review. Histol. Histopathol. 12: 883-892. 